\section{$\underset{\substack{\text { hommes } \\ \text { \& migrations }}}{ }$}

\section{Hommes \& migrations}

Revue française de référence sur les dynamiques

migratoires

1319 | 2017

Réfugiés et migrants au Liban

\title{
Shumona Sinha, Apatride
}

Paris, éd. de l'Olivier, 2016, 188 p., 17,50 €.

\section{Mustapha Harzoune}

\section{Q OpenEdition}

12 Journals

\section{Édition électronique}

URL : http://journals.openedition.org/hommesmigrations/4029

DOI : 10.4000/hommesmigrations.4029

ISSN : 2262-3353

\section{Éditeur}

Musée national de l'histoire de l'immigration

\section{Édition imprimée}

Date de publication : 1 octobre 2017

Pagination : 195-196

ISBN : 978-2-919040-39-1

ISSN : 1142-852X

\section{Référence électronique}

Mustapha Harzoune, «Shumona Sinha, Apatride», Hommes \& migrations [En ligne], 1319 | 2017, mis en ligne le 01 octobre 2017, consulté le 08 janvier 2021. URL : http://journals.openedition.org/

hommesmigrations/4029; DOI : https://doi.org/ERREUR PDO dans/localdata/www-bin/Core/Core/ Db/Db.class.php L.34 : SQLSTATE[HY000] [2006] MySQL server has gone away 
sentent coupables ». Comprendre aussi pourquoi Maryam Madjidi "déterre tes mortsenécrivant ". Ces morts, cesonttes combattants de la liberté, héritiers d'un Hafez qui invitait à ne pas tomber "dans te piègedel'hypocrisiecommeceux-làqui ont salite Coran ".

Et puis illy a la france. "Je voudrais me taire quandonmedemandemes origines. te voudrais raconter autre chose, n'im= porte quoi, inventer, mentir. Je voudrais aussi quion me pose d'autres questions inattendues, déroutantes, mêmes absurdes, qu'on me surprenne. Et en mêmetemps,jemevautredans monpetit monde exotique et j'en tire une fierté jouissive. La fierté d'être différente. Mais toujours cette petite voix intérieure qui me rappette que tout ca ce n'est pas moi, queje me cache derrière un masque, cetui de l'exilée romanesque. Je vous te donne ce masque, prenez-te, je te dépose entre vos mains." Et les masques tombent, à commencer par celui de la "douteur refoutée "- on pense à Doan Bui.Cescauchemars et ces dessins terrifiants d'une enfant, d'une " survivante ". Ses combats (et ses victoires) à lécole et comment it fallut "avater sa langue" pour triom= pherdans " latangue des Lumières et de Aolière ". Plus tard, la femme toujours hantée par quetques fantômes, continuera d'entendre la voix consolatrice et résiliente, de sa grand-mère.

Hfaut aussi passer "d'unmonde à lautre, d'une tangue à l'autre " et "jongter avec tesidentités $》$. Ilest juste ators de rabattre te caquet de ceux pour qui la double eulture est une richesse quand on "vacille toutle temps, d'un bordàlautre" et d'être "en colère contre ces hypocrites qui s'extasient sur une blessure ". Faute du bon outillage conceptuel, la " blessure" peut faire "glisser sur son identité ". Et "tomber" ! Comme lors de ce premier retour à Téhéran où la jeune femme a risqué de "briser toutes les colonnes de sa vie». Un livre à mettre entre les mains de tous les gamins de France. Et de quelques caciques encore perchés.

M. H.

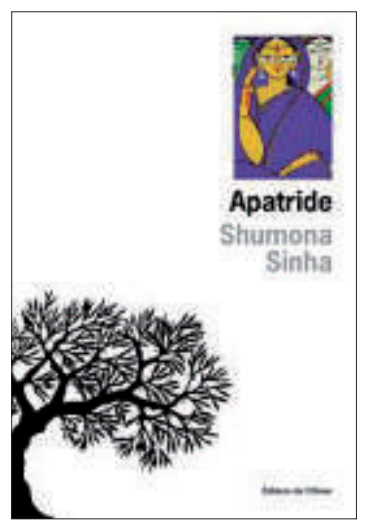

Shumona Sinha Apatride Paris, éd. de L'Olivier, 2016, 188 p., $17,50 €$

"Apatride", le mot claque et sa sécheresse dérange. À lui seul, il porte sa charge symbolique et son poids de préjugés. Mais, qu'est ce qui fait, aujourd'hui, l'apatride? La croisée des chemins, des trajectoires entrelacées, des origines mêlées, des opinions rebelles; ce qui relègue au " pas d'ici », à l'« étrangeté », l'« indocilité », l'« utopique ». Le "hors sol ». Apatrides! L'étrangère confrontée à une administration suspicieuse, en butte aux idées reçues et hostiles. L'enfant adopté qui ignore tout de ses origines et de ses parents biologiques. L'indienne entraînée dans une lutte inégale contre des forces politiques et économiques alliées. Apatrides, dans ce monde d'hommes, ces femmes privées du droit d'exister et d'aimer. Nationalistes et communautaristes (hindouistes ou musulmans), égoïstes, racistes ou imbéciles, affameurs de pain 


\section{LIVRES}

et de liberté, machistes de tout poil, voilà réunis les ressorts d'une machine folle, productrice en série d'apatrides. À l'image des trois femmes du roman.

Esha, prof d'origine indienne, a déposé une demande de naturalisation. Elle constate et subit, angoissée, l'inculture, l'homophobie, le sexisme, l'antisémitisme, l'agressivité de ses élèves grimés d'une religiosité de bazar. Française d'origine indienne, Marie part en Inde en quête de ses parents biologiques et s'adonne à un trouble activisme politique. Mina, la jeune indienne embarquée dans une lutte de paysans contre le pouvoir local voue d'ailleurs à Marie une "vénération mêlée de méfiance". Enceinte, la naïve Mina croit que Sam, l'enfant de bonne famille, va l'épouser et lui éviter le déshonneur. Marie et Esha se sont rencontrées, elles, sur les réseaux sociaux.

Apatride désigne ces hommes et ces femmes brinquebalés par la marche chaotique d'un monde où plus une parcelle n'échappe aux mêmes peurs, bouleversements, injustices, incertitudes. Où les femmes subissent, partout, la surveillance et le regard "baveux" des hommes. Un monde où, sous l'action des " sources souterraines de la violence (...) le sol pouvait se fissurer et s'effondrer partout sur la terre ». Les mêmes violences, religieuses ou communautaires, frappant l'Inde comme l'Europe. Même en France, l'athéisme (re)devient «tabou »! On y croise des gens "qui croyaient qu'au-delà des nuages ily avait un barbu, deux, trois barbus, son fils, la mère et la pute, les mille deux cents vierges, toute une clique, et qu'ils allaient bientôt rétablir le pouvoir du plus grand, qu'ils allaient provoquer un bain de sang au nom de sa clémence et de sa magnanimité. "

Létranger doit endurer la suspicion de ceux, " désormais décomplexés, culottés, affranchis ", qui transforment le monde en " une pyramide dans laquelle on montait de l'obscurité des bas-fonds vers la lumière, vers la blancheur, vers la race meilleure ». Rien pour séduire le vulgum pecus. Le doute d'ailleurs gagne Esha: cette naturalisation pourrait-elle devenir " un fardeau en plus, celui de devoir prouver la légitimité de ce qu'elle posséderait désormais et qui serait vu comme un privilège" ? Elle regrette aussi "l'indifférence de ses compatriotes, suspendus dans le vide, entre deux pays, entre deux continents ». Indifférents " au bonheur et au malheur d'ici", "soucieux que de se cacher dans les trous de la ville, dans les creux du temps, et de survivre, comme les cafards". Pire! Certains de ceux qui " avaient franchi les frontières » ont fait de ce pays un "foutoir géant ", "où ilfallait côtoyer des tas de gens dont les actes et les codes sont sous l'emprise de la religion, où être une femme était un fardeau et s'exposer au monde des hommes un pêché, elle aurait préféré vivre ailleurs, dans un autre pays, une autre époque". De l'Inde à la France, Shumona Shina dénonce, sans concessions, les fabriques modernes de l'apatride. La structure alourdie d'épisodes entrés aux forceps entremêle les sociétés. Et les destins.

M. H. 